\title{
A pathway design framework for national low greenhouse gas emission development strategies
}

Waisman, Henri; Bataille, Chris; Winkler, Harald; Jotzo, Frank; Shukla, Priyadarshi; Colombier, Michel; Buira, Daniel; Criqui, Patrick; Fischedick, Manfred; Kainuma, Mikiko

Total number of authors:

40

Published in:

Nature Climate Change

Link to article, DOI:

10.1038/s41558-019-0442-8

Publication date:

2019

Document Version

Peer reviewed version

Link back to DTU Orbit

Citation (APA):

Waisman, H., Bataille, C., Winkler, H., Jotzo, F., Shukla, P., Colombier, M., Buira, D., Criqui, P., Fischedick, M., Kainuma, M., La Rovere, E., Pye, S., Safonov, G., Siagian, U., Teng, F., Virdis, M. R., Williams, J., Young, S., Anandarajah, G., ... Trollip, H. (2019). A pathway design framework for national low greenhouse gas emission development strategies. Nature Climate Change, 9(4), 261-268. https://doi.org/10.1038/s41558-019-0442-8

\section{General rights}

Copyright and moral rights for the publications made accessible in the public portal are retained by the authors and/or other copyright owners and it is a condition of accessing publications that users recognise and abide by the legal requirements associated with these rights.

- Users may download and print one copy of any publication from the public portal for the purpose of private study or research.

- You may not further distribute the material or use it for any profit-making activity or commercial gain

- You may freely distribute the URL identifying the publication in the public portal 
Henri Waisman, Chris Bataille, Harald Winkler, Frank Jotzo, Priyadarshi Shukla, Michel Colombier, Daniel Buira, Patrick Criqui, Manfred Fischedick, Mikiko Kainuma, Emilio La Rovere, Steve Pye, George Safonov, Ucok Siagian, Fei Teng, Maria-Rosa Virdis, Jim Williams, Soogil Young, Gabrial Anandarajah, Rizaldi Boer, Yongsun Cho, Amandine Denis-Ryan, Subash Dhar, Maria Gaeta, Claudio Gesteira, Ben Haley, Jean-Charles Hourcade, Qiang Liu, Oleg Lugovoy, Toshihiko Masui, Sandrine Mathy, Ken Oshiro, Ramiro Parrado, Minal Pathak, Vladimir Potashnikov, Sascha Samadi, David Sawyer, Thomas Spencer, Jordi Tovilla, Hilton Trollip

\section{A pathway design framework for national low greenhouse gas emission development strategies}

Originally published in:

Nature Climate Change

9 (2019), 261-268

DOI: $10.1038 / s 41558-019-0442-8$ 
This is the author's version of a work that was accepted for publication. Changes resulting from the publishing process, such as editing, corrections and structural formatting, may not be reflected in this document. Changes may have been made to this work since it was submitted for publication. A definitive version was subsequently published in the Journal cited above. 


\title{
A pathway design framework for national low greenhouse gas emission development strategies
}

\author{
Author's Accepted Manuscript
}

Citation: Waisman, Henri, et al. "A pathway design framework for national low greenhouse gas emission development strategies." Nature Climate Change 9.4 (2019): 261.

doi: https://doi.org/10.1038/s41558-019-0442-8

URL on publisher's website: https://www.nature.com/articles/s41558-019-0442-8

Henri Waisman ${ }^{1,}{ }^{*}$, Chris Bataille ${ }^{1}$, Harald Winkler ${ }^{2}$, Frank Jotzo ${ }^{3}$, Priyadarshi Shukla ${ }^{4}$, Michel Colombier ${ }^{1}$, Daniel Buira ${ }^{5}$, Patrick Criqui ${ }^{6}$, Manfred Fischedick ${ }^{7}$, Mikiko Kainuma ${ }^{8}$, Emilio La Rovere ${ }^{9}$, Steve Pye ${ }^{10}$, George Safonov ${ }^{11}$, Ucok Siaigian ${ }^{12}$, Fei Teng ${ }^{13}$, Maria-Rosa Virdis ${ }^{14}$, Jim Williams ${ }^{15}$, Soogil Young ${ }^{16}$, Gabrial Anandarajah ${ }^{10}$, Rizaldi Boer ${ }^{17}$, Yongsun $\mathrm{Cho}^{18}$, Amandine Denis-Ryan ${ }^{19}$, Subash Dhar $^{20}$, Maria Gaeta ${ }^{21}$, Claudio Gesteira ${ }^{9}$, Ben Haley ${ }^{22}$, Jean-Charles Hourcade ${ }^{23}$, Qiang Liu ${ }^{24}$, Oleg Lugovoy ${ }^{25}$, Toshihiko Masui ${ }^{26}$, Sandrine Mathy ${ }^{6}$, Ken Oshiro ${ }^{27}$, Ramiro Parrado ${ }^{28}$, Minal Pathak ${ }^{4}$, Vladimir Potashnikov ${ }^{25}$, Sascha Samadi ${ }^{7}$, David Sawyer ${ }^{29}$, Thomas Spencer ${ }^{1}$, Jordi Tovilla ${ }^{5}$, Hilton Trollip ${ }^{2}$

${ }^{1}$ Institut du Développement Durable et des Relations Internationales, Sciences Po, France

${ }^{2}$ Energy Research Centre, University of Cape Town, South Africa

${ }^{3}$ Australian National University, Australia

${ }^{4}$ Global Center for Environment and Energy, Ahmedabad University, India

${ }^{5}$ Tempus Analitica, Mexico

${ }^{6}$ Université de Grenoble Alpes/ CNRS/ INRA/ Grenoble INP/GAEL, France

${ }^{7}$ Wuppertal Institute for Climate, Environment and Energy, Germany

${ }^{8}$ Institute for Global Environmental Strategies, Japan

${ }^{9}$ Centroclima/PPE/COPPE/UFRJ, Brazil

${ }^{10}$ University College London, UK

${ }^{11}$ National Research University, Higher School of Economics, Russia

${ }^{12}$ Center for Research on Energy Policy, Bandung Institute of Technology, Indonesia

${ }^{13}$ Institute of Energy, Environment and Economy, Tsinghua University, China

${ }^{14}$ Agenzia nazionale per le nuove tecnologie, I'energia e lo sviluppo economico sostenibile, Italy

${ }^{15}$ University of San Francisco, USA

${ }^{16} \mathrm{KDI}$ School of Public Policy and Management, Korea

${ }^{17}$ Center for Climate Risk and Opportunity Management, Bogor Agricultural University, Indonesia

${ }^{18}$ Korea Energy Economics Institute, Korea

${ }^{19}$ ClimateWorks Australia, Australia

${ }^{20}$ UNEP-DTU Partnership, Technical University of Denmark, Denmark

${ }^{21}$ Ricerca sul Sistema Energetico - RSE S.P.A., Italy

${ }^{22}$ Evolved Energy Research, USA

${ }^{23}$ Centre International de Recherche sur I'Environnement et le Développement, France

${ }^{24}$ National Center for climate change Strategy and international Cooperation, China

${ }^{25}$ Russian Presidential Academy of National Economy and Public Administration, Russia

${ }^{26}$ National Institute for Environmental Studies, Japan

${ }^{27}$ Mizuho Information \& Research Institute, Inc., Japan

${ }^{28}$ RFF-CMCC European Institute of Environmental Economics, Centro Euro-Mediterraneo sui

Cambiamenti Climatici \& Università Ca' Foscari Venezia, Italy

${ }^{29}$ EnviroEconomics, Canada

* corresponding author, email: henri.waisman@iddri.org (ORCID ID: https://orcid.org/0000-0001$\underline{7450-4912 \text { ) }}$ 


\section{Abstract}

The Paris Agreement introduces long-term strategies as an instrument to inform progressively more ambitious emission reduction objectives, whilst holding development goals paramount in context of national circumstances. In the lead up to COP21, the Deep Decarbonization Pathways Project developed mid-century low-emission pathways for 16 countries, based on an innovative pathway design framework. In this Perspective we describe this framework and show how it can support the development of sectorally and technologically detailed and policy-relevant country-driven strategies consistent with the Paris Agreement climate goal. We also discuss how this framework can be used to engage stakeholder input and buy-in; design implementation policy packages; reveal necessary technological, financial and institutional enabling conditions; and support global stock-taking and ratcheting of ambition. 
The climate goal of the Paris Agreement (PA) is to hold "the increase in the global average temperature to well below $2^{\circ} \mathrm{C}$ above pre-industrial levels and pursuing efforts to limit the temperature increase to $1.5^{\circ} \mathrm{C}^{\prime \prime}$ (Art. 2.1). This requires net-zero greenhouse gas (GHG) emissions in the second half of the century (Art. 4.1), as a necessary condition to stay within the remaining cumulative emissions budget of approximately $600-1200 \mathrm{Gt} \mathrm{CO}_{2} \mathrm{e}$ in the 21st century. ${ }^{1,2}$ No region nor sector is exempt from this requirement; any excess emissions must be compensated with negative emissions.

The PA requires Parties to submit Nationally Determined Contributions (NDCs), representing voluntary commitments formulated by each country at a 10-15 year horizon in the light of the above collective objective (Art. 3 and 4.2). These NDCs are to be designed within the context of other development goals defined by national circumstances (PA preamble), including the Sustainable Development Goals (SDGs) relating to energy access and security, air quality, poverty alleviation, and employment creation. ${ }^{3,4}$ Given the widely acknowledged lack of collective ambition in the first round of NDCs, the PA requires Parties to submit a revised, more ambitious NDC every five years (Art. 4.3 and 4.9 ). The PA also mandates Global Stocktaking exercises every five years to assess progress against the collective objective (Art 14).

To inform these processes, country parties are invited to "formulate and communicate long-term low GHG emission development strategies" (Art. 4.19), filed with the United Nations Framework Convention on Climate Change. We argue here that these long-term strategies can be a central enabling instrument for reconciling the long-term and global nature of the climate objective with the medium term horizon and national scale of the NDCs, and thus inform policy. Strategies based on pathways reverse forecasted from the long term goal to the present, or "backcasted", would ensure consistency of national near-term planning, investment and policy decisions with long term social, economic and environmental goals in the context of inertia, lock-in risks, and mitigation innovation. ${ }^{5,6}$ Using backcasted pathways, strategies can also reveal the key international enabling conditions required for nations to adopt ambitious mitigation, such as technology development and transfer, finance for investment and adaptation, and institutional support.

For a long-term strategy to play these roles it must be sufficiently understood and accepted by a working majority of stakeholders, both those responsible for implementation and those affected by the transformation (e.g. governments, indigenous peoples' organizations, sector associations, firms, energy utilities, unions, experts, households, non-governmental organizations, etc.). To enable this, a process is required to educate these stakeholders, gather their essential inputs, and create a structured space for dialogue among them to design and rigorously debate such pathways. This requires that the strategies be formulated in a qualitative or semi-quantitative language understandable to all stakeholders. But it also requires they be expressed in comparable quantitative scenarios, characterized by economy-wide, internally consistent sets of parameters describing the evolution of emissions drivers at the sectoral level, as well as key socioeconomic and development indicators.

The first section identifies four key methodological principles to develop and combine qualitative narrative strategies with quantitative scenarios that can feed into national and global pathway development processes. We then describe how these methods were developed and used in the Deep Decarbonization Pathways Project (DDPP). The third section, A Paris-compatible pathway design 
framework, synthesizes the approach by articulating them in a consistent pathways design framework, before we conclude with implications, recommendations and further research needs.

\section{Methodological challenges to inform the post-Paris process}

There is already a rich literature on global low emissions scenarios using Integrated Assessment Models (IAMs) ${ }^{7}$, which formed the backbone of analysis in the Intergovernmental Panel on Climate Change $5^{\text {th }}$ Assessment Report (IPCC AR5) ${ }^{1}$. This "data spine" helped demonstrate that a global low emission pathway is possible, while clarifying that the global temperature goal of "well below $+2^{\circ} \mathrm{C}^{\text {" }}$ requires reducing global emissions to net-zero and likely net-negative around 2050 or soon after. ${ }^{1,2}$ Recent studies on ambitious climate goals from this literature have analysed socio-economic aspects such as economic growth and fossil fuel availability ${ }^{8}$, the distributional consequences among major economies ${ }^{9}$, and the interplay with the SDGs ${ }^{10}$. Some studies have also assessed the effect of current NDCs on achieving the PA climate objective ${ }^{11}$, and the conditions for reaching $1.5^{\circ} \mathrm{C}$ climate stabilization. ${ }^{2}$ Country-level scenarios consistent with ambitious mitigation objectives have even been investigated through multi-model comparisons, e.g. for Asian countries ${ }^{12}$ and Latin American countries. ${ }^{13}$

This global IAM approach has limitations, however, that need to be addressed for supporting the national policy processes envisaged in the PA. ${ }^{14-16}$ On the practical side, IAMs are resource intensive models that require specialized teams to build and run, beyond the capacity of many countries and of most national actors who would like to contribute to policy debate and planning. In addition, the IAM storylines are arranged in "Shared Socioeconomic Pathways" ${ }^{8}$, which do not distinguish technological and policy deviations due to individual country circumstances. Finally, the mathematical representation of complex climate-economy systems in global IAMs requires simplifications that limit their ability to represent specific national circumstances, objectives and policy approaches. ${ }^{17}$ IAMs conventionally adopt aggregate sectoral and regional representations as well as simplified economic and behavioural assumptions that can miss country specific mitigation options and limitations. ${ }^{18}$ These modelling choices lead to a superficially simple focus on priceoriented mitigation policies based on cost-benefit approaches ${ }^{19}$, restricting consideration of a wider range of policy instruments ${ }^{20,21}$ and objectives. In particular, many IAMs face structural challenges including context-specific aspects of non-climate co-benefits or costs. ${ }^{22}$

There is also a "bottom-up" literature ${ }^{23}$, designed around national circumstances and policy, which conducts country-scale investigation of development and ambitious climate objectives for a wide range of countries across Asia ${ }^{24-28}$, Latin America ${ }^{29-34}$, Africa ${ }^{35,36}$, Europe ${ }^{37-43}$ and North America. ${ }^{44-49}$ Several studies describe multi-country exercises in which country teams co-explored their domestic pathways. ${ }^{50-52}$ To date, these studies have, however, lacked the overarching global context inherent in the IAM approach because the boundary conditions of national studies are not systematically defined according to a consistent cross-country vision the global transformation (e.g. carbon budgets, technological assumptions on learning and transfer, fossil fuel prices and their supply, international demand assumptions, etc.). ${ }^{53}$

We propose a new approach is needed to support the PA, one that combines key elements of the global IAM and national bottom-up modelling literatures to provide a structured global context for policy-relevant analyses of national low greenhouse gas emission development strategies. Its purpose would be to allow formation of national strategies consistent with country circumstances, 
place-specific development objectives and national political priorities, reflecting a coherent crosscountry global context, and compatible with the collective ambition towards the temperature goal. ${ }^{11}$

This hybrid approach requires that four key methodological challenges are addressed.

First, the design of low emissions strategies is faced with many global and country-specific uncertainties, making necessary a multi-scenario approach exploring different plausible futures. To support the design of robust national strategies and policies, the different futures must be defined from the key uncertainties affecting most importantly the trajectory of the specific country considered.

Second, to be useful for policymaking, quantitative national scenarios should not only describe emissions trajectories but also provide transparent sectoral detail of the broader social, economic and technological changes within which they are founded. Modelling is useful for this purpose, but no single model is able to encompass all the sectoral and socio-economic indicators required to characterize development trajectories. A flexible, inclusive approach to modelling is needed.

Third, comparability across different countries is also important to facilitate knowledge sharing and enable a global composite to emerge from national visions. This requires a systematic quantitative structure identifying key sectoral and development metrics and built to accommodate scenarios from different sources. We refer to this reporting structure as a "dashboard".

Fourth, pathways analysis should help identify the options to reach mid-century development objectives and emissions neutrality starting from the present. The design of these pathways starts from the definition of realistic 2050 benchmark values for the key indicators listed in the dashboard. A backcasting approach is then needed to identify the systemic changes required to move these indicators from their present values to ranges in line with these benchmarks.

In the following section, we provide insights on how to concretely address these challenges through an approach that is bottom-up, country-driven, policy-relevant and consistent with a global mitigation goal. We derive these insights by documenting methodological lessons from the Deep Decarbonization Pathways Project (DDPP) ${ }^{54-56}$, wherein sectorally detailed mitigation scenarios were designed to reflect national development and political circumstances according to the above four principles. The project, coordinated by the Institute for Sustainable Development and International Relations (IDDRI) and the Sustainable Development Solutions Network (SDSN), was composed of country research teams from 16 developed and emerging economies representing $74 \%$ of 2010 global energy-related $\mathrm{CO}_{2}$ emissions. The DDPP studies subsequently influenced the climate policy debate in several of these countries..$^{57,58}$

This paper does not focus on the details of the DDPP results as published in 2015-16 for two reasons. First, because the DDPP was conducted before COP21, the climate objective was chosen as a $50 \%$ probability of maintaining $2^{\circ} \mathrm{C}$, therefore less ambitious than the "well below $2^{\circ} \mathrm{C} .$. towards $1.5^{\circ} \mathrm{C}^{\prime}$ framing introduced in the PA. Second, while some DDPP teams included land use and fugitive emissions, the aggregate project results focused on energy-related combustion and process emissions, hence failing to capture all GHG sources. In this paper, we will discuss the methodological lessons that were learned from the DDPP and would be useful for implementation of the PA. In Conclusions, we discuss how a DDPP-type exercise could be re-done with the PA framing, i.e. 
considering more ambitious climate objectives and non-energy emissions, especially from the landuse sector.

\section{Guidelines for national low emission development pathways}

We describe below key features of the DDPP method, designed to address the challenges presented in above. They constitute the four building blocks of the DDPP pathways design framework, synthesized in in the next section, A Paris-compatible pathway design framework.

\subsection{Country driven strategies in a context of deep uncertainty}

In the DDPP, given the focus on energy-related emissions, the strategies were structured around three key drivers: 1) energy efficiency and conservation, including structural and behavioural changes; 2) decarbonization of energy carriers (electricity, heat, liquids and gases); and 3) end-use switching to these low-carbon carriers. How these three "pillars of decarbonization" were applied, however, depended on national circumstances, including a country's development priorities, institutions, economic structure, political situation, endowment in renewable energy and other key resources, and many other factors.

A multi-decade evolution of technologies, socio-economic conditions and politics ${ }^{17,59}$, such as that associated with a transition to a net-zero energy system ${ }^{60}$, is characterized by "deep uncertainty". ${ }^{61}$ In this context, standard methods for risk and decision analysis ${ }^{62}$, based on probability distributions surrounding a "best-guess" of the future, may not be appropriate. Instead, the identification of different strategies in response to various plausible futures supports an adaptive decision-making process $^{63}$ that allows policymakers to learn and adjust to evolving information, technology and events. ${ }^{64,65}$ This approach allows definition of robust strategies which perform well under a range of future conditions. ${ }^{66}$

Each country team in the DDPP therefore developed a small number of internally consistent narrative strategies, developed and expressed in the language of stakeholders. All strategies implement the three pillars of decarbonisation, but each variant reflects sensitivity to key uncertainties, as freely chosen by the country teams according to their national circumstances. Some teams focussed on international conditions, e.g. the oil price in the Canadian DDPP study ${ }^{67}$, which drove oil production volumes during the transition. Others focussed on socio-economic drivers, e.g. labour skills profiles in the South African DDPP study ${ }^{68}$, which determined the plausibility of alternative low GHG economic structures. The Italian study ${ }^{69}$ addressed the social acceptability of carbon capture and storage. The Indian team ${ }^{70}$ focussed on the policy implications of climate-centric vs. sustainable development approaches to GHG emissions. The French team ${ }^{71}$ explored different strategies under varying effectiveness of energy efficiency programs, notably in the building sector.

\subsection{Modelling development pathways}

National models play a key role in translating the above narrative strategies into quantified scenarios, consistently assessing key socio-economic and technological indicators. The socio-economic metrics non-exclusively include unemployment rates, skills profiles and population in income classes (South Africa $\left.{ }^{68}\right)$, the import dependency index $\left(\operatorname{Japan}^{72}, \operatorname{India}^{70}\right.$ and Germany $\left.{ }^{73}\right)$, local air pollutant levels $\left(C_{\text {China }}{ }^{74}\right.$, India $\left.^{70}\right)$, and the energy poverty index $\left(\mathrm{UK}^{75}\right)$. Country-relevant identification of these 
indicators and their assessment in a transparent manner is key to the design and sharing of strategies by public and private decisionmakers and stakeholders.

Different model types are appropriate for different scales and sectors. The DDPP pathway design framework (synthesized in Section 3) was conceived to accommodate different modelling paradigm and tool, as appropriate for quantification given the specific focus of the analysis. ${ }^{76}$ The choice of models and their level of complexity should be made whilst considering their capacity to inform the practical needs of political dialogue and policy formation. ${ }^{2,3}$ The modelling approach must also be pragmatic and sensitive to ease-of-use, data availability, budget and timescales.

The national DDPP studies were supported by a variety of modelling tools, chosen by the research teams in each context, with varying areas of focus and level of detail. ${ }^{23}$ The DDPP study of South Africa investigated poverty alleviation and unemployment reduction ${ }^{68,77}$, combining an energy system model with a computable general equilibrium (CGE) model that portrayed disaggregated labour skill classes and their sectoral employment. The Japanese analysis focussed on energy security concerns $^{72,78}$, requiring a detailed energy supply and demand bottom-up model. The study for China highlighted the air quality co-benefits of mitigation by coupling energy system and air pollution models. ${ }^{74}$ The study of India combined analysis of air quality and energy security benefits. ${ }^{70}$ The Australian analysis included dedicated analysis of land-based sequestration options, requiring a land use model. ${ }^{79} \mathrm{~A}$ key focus of the Brazilian study was on inequality and land use, employing a hybrid CGE model which portrayed the evolution of income distribution across household income classes while also including biofuel, agriculture and forestry mitigation options. ${ }^{80}$ The study of the USA discussed issues posed by integration of substantial variable electricity generation combined with electricity based synthetic hydrocarbon production, requiring the use of a dispatch model. ${ }^{81}$

\subsection{Scenario data reporting}

Model outputs vary from one tool to the other, depending on paradigm, research focus, and scope, which can lead to stakeholder confusion and difficulties in policy design and implementation. A consistent set of comparable and quantified results gathered in a spreadsheet "dashboard", reported systematically across modelling tools and country studies, can serve three complementary purposes relevant to the post-Paris process.

First, the dashboard serves as a "driver dictionary". It expresses the main determinants of a country's sectoral transformation through a common language, enabling cross-country comparisons, benchmarking and learning. These commonly defined drivers allow a country team to compare its ambition with the collective requirements characterized by sectoral benchmarks (see Backcasting using long-term benchmarks).

Second, the dashboard variables characterize the physical sectoral and sub-sectoral transformations at a sufficient level of granularity and technical transparency for dialogue with sectoral and technology experts. This detailed information can serve policy instrument selection within the context of sectoral and national circumstances.

Third, the dashboard serves as an aggregator in a bottom-up approach, where the global vision emerges as a composite of sectoral and national pathways. Beyond emissions accounting, the dashboard allows a physical view of the global transformations (e.g., solar panel capacity, number of 
electric vehicles). This information can serve, along with analysis of learning rates and economies of scale, as inputs for assessment of investment needs at the national and global level. ${ }^{56}$ This enables a transparent analysis and discussion of where global-scale cooperation is needed to decarbonize key sectors such as power generation, transport and industry, including technology development and transfer, financing, and institutional capacity. ${ }^{82,83}$

Given the focus of the DDPP on energy-related emissions, the dashboard was based on a decomposition of activity, energy intensity and energy mixes for key energy end-use demands (i.e. buildings, transport and industry) and energy supply (i.e. electricity, liquids and gases). In addition, the dashboard included cumulative data on power generation capacities (in GW, by technology), passenger vehicles (number of vehicles by energy type) and liquid energy carriers (in EJ) ${ }^{54,56}$; see supplement for full detail of dashboard content in the DDPP.

\subsection{Backcasting using long-term benchmarks}

To guide their self-determined contributions to the global effort, countries need to identify national pathways that satisfy key long-run socio-economic objectives, reach very low GHG emission levels, and maximize co-benefits, all in an economically efficient way. Approaching these pathways as country-driven back-casts from these objectives puts the long run constraint at the center of the process, questioning how short-term investment and policy choices affect the capacity to reach longterm objectives. This approach directly confronts analysts with the consequences of potential sector lock-ins and stranded assets (e.g. investments in coal plants, NG networks or LNG terminals and their potential for retrofitting with CCS or renewable methane), and the necessary domestic and international conditions to avoid them, notably when considering long lived assets like infrastructure, buildings and industrial facilities. ${ }^{83}$

Country teams, governments or other parties, working independently on their national pathways, need ex-ante guidance to define the necessary physical transformations to meet their emissions and development objectives. To this aim, common overall and sectoral benchmarks can be used that are mapped against the variables listed in the dashboard. These benchmarks characterize the scale and detail of transformative change required by 2050 to achieve the objective of net-zero emissions in the second half of the century, or by 2050 in the case of $1.5^{\circ} \mathrm{C} .^{2}$

In the DDPP, the benchmarks for emission levels in 2050 compatible with a given climate objective and corresponding sectoral emissions intensities were based on the IAM informed global averages from Working Group III (WG3) of the IPCC AR5. For example, an electricity sector generation benchmark for 2050 was set at -30 to +50 grams $\mathrm{CO}_{2} / \mathrm{kWh}$, based on Ch.7 WG3 AR5 "Energy Systems", Fig. 7.7. ${ }^{84}$

To ensure a coherent cross-country global context, collective assumptions were also made regarding the availabity of some technologies that would depend on large-scale R\&D involving international cooperation and transfer. The nature and speed of the deployment of the technologies and the corresponding domestic sectoral transformations towards the common benchmarks would then differ by country, according to national circumstances and priorities affecting the relevance of different options. For example, the above electricity benchmark could be reached through different power generation mixes according to country circumstances (e.g., endowment of renewables and capacity to balance them, storage capacity for carbon capture, or social acceptability of nuclear). 
Another key example included the eventual adoption by all teams of combinations of electric, biofuel or hybrid personal vehicles as a key strategy to decarbonize passenger transport.

The next sections discusses how this backcasting approach using long-term benchmarks is embedded in the complete DDPP pathways design framework, built from the four points discussed in this section.

\section{A Paris-compatible pathway design framework}

In the DDPP pathways design framework, synthesized in Figure 1, the process began with the definition of multiple country-driven strategies reflecting key uncertainties. These narrative strategies were then converted into quantitative scenarios with technical, social and economic characteristics using analytical assessment tools, including national-scale models but also other tools as appropriate. Transparent and detailed scenario results were then reported against a common set of indicators in the dashboard. These results were analysed to assess if the domestic emissions and socioeconomic indicators, as well as cumulative global emissions, were consistent with the backcasted benchmarks. ${ }^{85,86}$

A key design point of the DDPP pathways design process was its iterative nature, supported by two learning processes. On the one hand, the dashboard results could be compared by the country teams against the benchmark national and sectoral emission drivers compatible with the collective climate objective. On the other hand, the common dashboard adopted by the different country teams enabled the comparison of assumptions across countries and learning about the possibility of different actions. These two learning processes led the teams to progressively revise their strategy and scenario assumptions, notably regarding technical potentials for decarbonisation in the different sectors. This allowed those that were initially out of compliance to meet and exceed the benchmarks, while the already ambitious went further. The resulting pathways presented in the DDPP country and global synthesis ${ }^{54}$ reports are the final outcomes of these iterations. They constitute a selfassessment by in-country researchers of what physical sector transformations can be chosen to put the domestic economy on track with the net-zero emissions objective. 


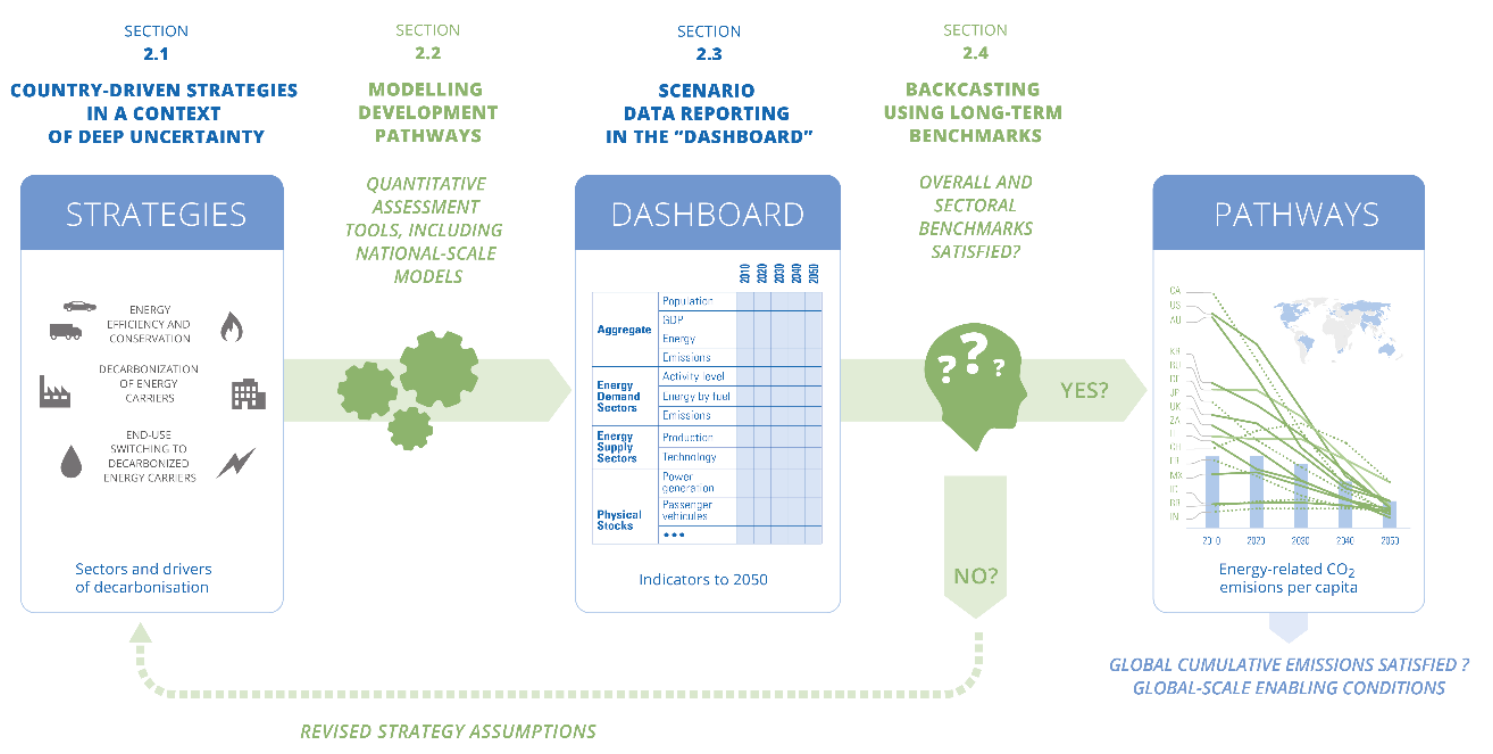

The DDPP results illustrate how the pathways design framework can help inform the key issues of ambition, cooperation and equity

First, this approach does not guarantee consistency with the climate goal as defined by cumulative global emissions. But, even if national cumulative emissions were not prescribed ex-ante, the resulting pathways were collectively compatible with the cumulative emission reductions required for the chosen climate objective. More specifically, when extrapolating emission trajectories to include all sources of emissions not explicitly covered in the DDPP (see Supplement for details), cumulative GHG emissions over 2010-2050 fell in the range of $1185-1555 \mathrm{Gt} \mathrm{CO}_{2}$. This is consistent with the $1166-1566 \mathrm{Gt} \mathrm{CO}_{2}$ range for $50 \%$ chance of $2^{\circ} \mathrm{C}$ (see Table SPM.1 WGIII AR5 in IPCC $(2014)^{1}$ ). These results provide a proof of concept for the DDPP approach to finding domestic mitigation actions countries could take to meet the global mitigation goal of the Paris Agreement.

Second, this approach also does not assume $a$ priori the exact nature of cross-country interactions. However, the DDPP results show how country-driven studies can inform the collective enabling conditions for the domestic mitigation actions to be possible, such as technology learning and transfer, or financial requirements to support investment needs. ${ }^{56,82}$ Such global assessment is made possible because country pathways are built from a coherent cross-country context on technology availability (see Backcasting using long-term benchmarks above), and because the individual country results were reported into a common dashboard, making possible the reconstruction of the global transformations emerging from national studies (see Scenario data reporting).

Finally, mindful that countries would favour different equity principles and criteria ${ }^{87,88}$, the analysis does not state how the costs or benefits of mitigation are to be shared among countries, nor how much each country contributes to the international cooperative efforts. The allocation of effort in support of other countries' domestic measures will be grounded in analysis of domestic and international equity ${ }^{88-90}$, including reference to norms of responsibility, capability, need, equality, and implications for international financial and technology transfers..$^{87,88,91-93}$ This analysis was beyond the scope of the analysis, and the DDPP analysis therefore does not directly define how the 
contributions that a country must submit under the Paris Agreement are "fair and ambitious" (decision 1/CP.21, para 27)." It does, however, provide a basis to assess this equity question from a bottom-up perspective against the physical regional and sectoral requirements of net-zero decarbonization, however they are paid for. A collective discussion and negotiation is one of the key purposes of the regular global stock take. Explicit documentation of global enabling conditions, as permitted by the above pathways design framework, is therefore a core input to the global stocktaking effort, which is to be viewed "in the light of equity" (Article 14.1).

\section{Conclusion}

New analytical processes and tools are needed to support the process codified in the PA. They should support the design of national low greenhouse gas emission development strategies that are consistent with global ambition and can support national policy formation and implementation. They should also inform the sectoral and international discussions needed to reveal the key points of global cooperation. Based on the DDPP, we have described principles and methodologies for such an approach. These include: the definition of multiple country-specific strategies framed by common drivers of decarbonisation in a context of deep uncertainty; the use of a variety of national modelling tools to translate narrative strategies into quantified scenarios and indicators reported in a common dashboard; and national and sectoral benchmarks to provide guidance towards collective midcentury mitigation ambition. These building blocks are combined in an iterative integrated framework for pathways design, encouraging cross-stakeholder communication and learning, enabling the assessment of compliance with national development and global emissions goals, and providing concrete support to policy formation in the context of the PA. This has direct practical implications for the revision of all countries' NDCs in 2020, and the formal stocktake under the UNFCCC in $2023 .^{6}$

The DDPP pathways design framework provides organizing principles for the definition of the national long-term strategies specified in the PA. It is not a methodology to be owned and run by a specific institution or government. It is rather an approach to support a shared process for strategy and pathway design among diverse groups of stakeholders to inform policy formation, which is eventually the responsibility of governments. It provides a structure for national governments to conduct stakeholder consultations to educate them, solicit their input, and identify mitigation measures and implementation policy packages. It also can help reveal key enabling conditions, such as technology development and transfer, finance for investment and adaptation, and institutional support, thus enabling more ambitious national NDCs. The framework could also be used by NonState Actors such as firms and sectoral associations, regional and city governments, NonGovernmental Organizations or international bodies to define their contribution to the Paris objectives. One important channel where the framework could be mobilized is the 2050 Pathways Platform initiative ${ }^{94}$ which aims to support nations, regions and cities seeking to devise long-term, net zero-GHG, climate-resilient and sustainable development pathways.

At the global level, the DDPP pathways design framework also provides a unifying frame for analysis of collective transition effects and implementation challenges from a national perspective. This could provide concrete insights into the collective conversation on global-scale cooperation in the 2023 Global Stocktake introduced in the Paris Agreement. The framework provides also an organizing 
principle for the emergence of a bottom-up literature on national transitions informing policy packages, in the context of global changes and objectives. As such, it could in particular provide a foundation for literature feeding into Chapter 4 of the future WG3 AR6 IPCC report, "Mitigation and development pathways in the near to mid-term".

Future work includes addressing the following priorities.

First, the DDPP methodology needs to be applied with the "well below $2^{\circ} \mathrm{C}$, towards $1.5^{\circ} \mathrm{C}$ " PA framing. This means notably adopting more ambitious benchmarks, consistent with global scale estimates from the IPCC $1.5^{\circ} \mathrm{C}$ Special Report. ${ }^{95}$ These revised benchmarks would help identify the additional physical sector changes required beyond those for $2^{\circ} \mathrm{C}$, and highlight where domestic action and international cooperation should be strengthened. This will involve a more granular analysis of challenging sectors such as transport and heavy industry. The latter, for example, requires analysis regarding enhancing technology R\&D, commercialization support and trade policies where it is necessary to protect and encourage first adopters of low, zero or negative emissions technologies. ${ }^{83}$ Non-energy emission sources should also be considered; the DDPP study on Indonesia provides a concrete example of how emissions from Agriculture, Forest and Land-Use can be treated using the DDPP methodology. ${ }^{96}$

Second, more countries, beyond the 16 analyzed explicitly here, must be included to improve representation of the global economy, especially developing economies. This will require programs to enhance the analytical capacities of developing countries, and a generalization of the DDPP framework methodological principles to capture the specifics of development challenges (e.g., access to modern energy services). To this effect, a regional DDPP network covering six Latin American countries - DDP-LAC - was launched in February 2018 in cooperation between the Inter-American Development Bank and IDDRI. A similar DDPP project in partnership with the German International Climate Initiative (IKI) - DDP-BIICS - that focusses on China, Brazil, South Africa, Indonesia and India was launched in December 2018.

Third, upfront decision maker and stakeholder involvement was in general low in the Phase I 2013-15 DDPP. The new DDP projects include an explicit engagement dimension with the objective of continuous dialogue with domestic decisionmakers to ensure broad ownership of the approach and the analysis. Engagement with policymakers is a mandatory component of DDP-LAC, including the offering to policymakers of a modelled low emissions development scenario to help inform their NDC. DDP-BIICS will go one step further by involving decisionmakers right from the start in the scenario design.

Fourth, global drivers matter for national based modelling (e.g. cumulative innovation and technology learning, projected fossil and renewable fuel prices and supply and demand throughout the transition ${ }^{53}$ ), and provide a fruitful avenue for cooperation between national and global IAM models. A clear mapping between national and global scales of analysis will be essential for clearly articulating enabling conditions for global technology development and transfer, finance for investment and adaptation, and institutional support, and will be key to the collective stocktaking dialogues.

Finally, the DDPP pathways design framework could provide a concrete articulation of theoretical principles identified by the social sciences transition literature for enabling constructive dialogue 
amongst stakeholders and decision-makers on system-wide transitions. ${ }^{17,59,97,98}$ Notably, the framework could be used to coordinate techno-economic modelling, socio-technical analysis and political analysis. Strategies, modelling, dashboards and pathways could be used for the alignment of conceptual languages, bridging of understanding of key ideas, and iteration of alternative visions until a working understanding is achieved amongst stakeholders and decision makers. ${ }^{99}$ Based on this, flexible and robust policy packages could be designed to meet national development and global emissions goals, taking into account the considerations of equity and poverty reduction referenced in Article 4.1. To deepen incorporation of these social science insights, new analytical tools and benchmarks are required to allow the translation from the hitherto standard techno-economic point of view to a broader perspective on low emissions development for all countries, e.g. based on the Sustainable Development Goals. The 2015 South African $^{68}$ and Indian DDPP reports ${ }^{70}$, which used explicit development indicators, provide examples of how this may evolve. 


\section{REFERENCES}

1. Edenhofer, O. et al. IPCC, 2014: Climate Change 2014: Mitigation of Climate Change. Contribution of Working Group III to the Fifth Assessment Report of the Intergovernmental Panel on Climate Change. (Cambridge University Press, 2014).

2. Masson-Delmotte, V. et al. IPCC Special Report: Global Warming of $1.5^{\circ} \mathrm{C}$. Summary for Policymakers. Intergovernmental Panel on Climate Change (2018).

doi:10.1017/CBO9781107415324

3. Winkler, H., Boyd, A., Torres Gunfaus, M. \& Raubenheimer, S. Reconsidering development by reflecting on climate change. International Environmental Agreements: Politics, Law and Economics 15, 369-385 (2015).

4. Shukla, P. R., Dhar, S. \& Mahapatra, D. Low-carbon society scenarios for India. Climate Policy 8, 156-176 (2008).

5. Sachs, J. D., Schmidt-traub, G. \& Williams, J. Pathways to zero emissions. Nature Geoscience 9, 799-801 (2016).

6. Rockström, J. et al. A Roadmap for Rapid Decarbonization. Science 355, 1-2 (2017).

7. Moss, R. H. R. H. et al. The next generation of scenarios for climate change research and assessment. Nature 463, 747-756 (2010).

8. O'Neill, B. C. et al. A new scenario framework for climate change research: The concept of shared socioeconomic pathways. Climatic Change 122, 387-400 (2014).

9. O'Neill, B. C. et al. The roads ahead: Narratives for shared socioeconomic pathways describing world futures in the 21st century. Global Environmental Change 42, 169-180 (2017).

10. von Stechow, C. et al. $2^{\circ} \mathrm{C}$ and SDGs: united they stand, divided they fall? Environmental Research Letters 11, 034022 (2016).

11. Rogelj, J. et al. Paris Agreement climate proposals need a boost to keep warming well below $2{ }^{\circ} \mathrm{C}$. Nature 534, 631-639 (2016).

12. Calvin, K. et al. The role of Asia in mitigating climate change: Results from the Asia modeling exercise. Energy Economics 34, S251-S260 (2012).

13. van der Zwaan, B., Calvin, K. \& Clarke, L. Climate Mitigation in Latin America: Implications for Energy and Land Use. Preface to the Special Section on the findings of the CLIMACAP-LAMP project. (2016). doi:10.1016/j.eneco.2016.05.005

14. Stern, N. Current climate models are grossly misleading. Nature 530, 407-9 (2016).

15. Pindyck, R. S. Climate Change Policy: What Do the Models Tell Us? Journal of Economic Literature 51, 1-23 (2013).

16. Chan, G., Carraro, C., Edenhofer, O., Kolstad, C. \& Stavins, R. Reforming the IPCC's Assessment of Climate Change Economics. Climate Change Economics 07, 1-16 (2016).

17. Geels, F. W., Berkhout, F. \& van Vuuren, D. P. Bridging analytical approaches for low-carbon transitions. Nature Climate Change 6, 576-583 (2016).

18. Staub-Kaminski, I., Zimmer, A., Jakob, M. \& Marschinski, R. Climate policy in practice: a 
typology of obstacles and implications for integrated assessment modeling. Climate Change Economics 05, 1440004 (2014).

19. Ackerman, F., DeCanio, S. J., Howarth, R. B. \& Sheeran, K. Limitations of integrated assessment models of climate change. Climatic Change 95, 297-315 (2009).

20. Scrieciu, S. Ş., Barker, T. \& Ackerman, F. Pushing the boundaries of climate economics: Critical issues to consider in climate policy analysis. Ecological Economics 85, 155-165 (2013).

21. Van Vuuren, D. P. et al. Alternative pathways to the $1.5^{\circ} \mathrm{C}$ target reduce the need for negative emission technologies. Nature Climate Change 8, 391-397 (2018).

22. Weyant, J. Some Contributions of Integrated Assessment Models of Global Climate Change. Review of Environmental Economics and Policy 11, 115-137 (2017).

23. Pye, S. \& Bataille, C. Improving deep decarbonization modelling capacity for developed and developing country contexts. Climate Policy 16, S27-S46 (2016).

24. Chen, W., Wu, Z., He, J., Gao, P. \& Xu, S. Carbon emission control strategies for China: A comparative study with partial and general equilibrium versions of the China MARKAL model. Energy 32, 59-72 (2007).

25. Jiang, K., Zhuang, X., Miao, R. \& He, C. China's role in attaining the global $2^{\circ} \mathrm{C}$ target. Climate Policy 13, 55-69 (2013).

26. Smith, J. B. et al. Development and climate change adaptation funding : coordination and integration Development and climate change adaptation funding : coordination and integration. Climate Policy 11, 37-41 (2011).

27. Shukla, P. R. \& Chaturvedi, V. Low carbon and clean energy scenarios for India: Analysis of targets approach. Energy Economics 34, S487-S495 (2012).

28. Fujino, J. et al. Back-casting analysis for $70 \%$ emission reduction in Japan by 2050 . Climate Policy 8, 108-124 (2008).

29. Grottera, C., Pereira, A. O. \& La Rovere, E. L. Impacts of carbon pricing on income inequality in Brazil. Climate and Development 5529, 1-14 (2015).

30. La Rovere, E. L., Burle Dubeux, C., Pereira, A. O. \& Wills, W. Brazil beyond 2020: from deforestation to the energy challenge. Climate Policy 13, 70-86 (2013).

31. La Rovere, E. L., Pereira, A. O., Dubeux, C. B. S. \& Wills, W. Climate change mitigation actions in Brazil. Climate and Development 6, 25-33 (2013).

32. Zevallos, P., Takahashi, T. P., Cigaran, M. P. \& Coetzee, K. A case study of Peru's efficient lighting nationally appropriate mitigation action. Climate and Development 6, 43-48 (2014).

33. Delgado, R., Cadena, A. I., Espinosa, M., Peña, C. \& Salazar, M. A case study on Colombian mitigation actions. Climate and Development 6, 12-24 (2014).

34. Sanhueza, J. E. \& Ladrón de Guevara, F. A. A case study of Chilean mitigation actions. Climate and Development 6, 34-42 (2013).

35. Winkler, H. Long Term Mitigation Scenarios. Strategic Options for South Africa 1-34 (2007).

36. Tyler, E., Boyd, A. S., Coetzee, K. \& Winkler, H. A case study of South African mitigation actions 
(For the special issue on mitigation actions in five developing countries). Climate and Development 6, 49-58 (2013).

37. Mathy, S., Fink, M. \& Bibas, R. Rethinking the role of scenarios: Participatory scripting of lowcarbon scenarios for France. Energy Policy 77, 176-190 (2015).

38. Schmid, E. \& Knopf, B. Ambitious mitigation scenarios for Germany: A participatory approach. Energy Policy 51, 662-672 (2012).

39. Strachan, N., Pye, S. \& Kannan, R. The iterative contribution and relevance of modelling to UK energy policy. Energy Policy 37, 850-860 (2009).

40. Usher, W. \& Strachan, N. Critical mid-term uncertainties in long-term decarbonisation pathways. Energy Policy 41, 433-444 (2012).

41. Pye, S., Sabio, N. \& Strachan, N. An integrated systematic analysis of uncertainties in UK energy transition pathways. Energy Policy 87, 673-684 (2015).

42. Chiodi, A. et al. Modelling the impacts of challenging 2050 European climate mitigation targets on Ireland's energy system. Energy Policy 53, 169-189 (2013).

43. Samadi, S., Terrapon-Pfaff, J., Lechtenböhmer, S. \& Knoop, K. Long-term low greenhouse gas emission development strategies for achieving the $1.5^{\circ} \mathrm{C}$ target - insights from a comparison of German bottom-up energy scenarios. Carbon Management 3004, 1-14 (2018).

44. Williams, J. H. et al. The technology path to deep greenhouse gas emissions cuts by 2050: the pivotal role of electricity. Science (New York, N.Y.) 335, 53-9 (2012).

45. McCollum, D., Yang, C., Yeh, S. \& Ogden, J. Deep greenhouse gas reduction scenarios for California - Strategic implications from the CA-TIMES energy-economic systems model. Energy Strategy Reviews 1, 19-32 (2012).

46. Paltsev, S., Reilly, J. M., Jacoby, H. D. \& Morris, J. F. The cost of climate policy in the United States. Energy Economics 31, S235-S243 (2009).

47. Ross, M. T., Fawcett, A. A. \& Clapp, C. S. U.S. climate mitigation pathways post-2012:

Transition scenarios in ADAGE. Energy Economics 31, S212-S222 (2009).

48. Tuladhar, S. D., Yuan, M., Bernstein, P., Montgomery, W. D. \& Smith, A. A top-down bottomup modeling approach to climate change policy analysis. Energy Economics 31, S223-S234 (2009).

49. Bataille, C., Tu, J. J. \& Jaccard, M. Permit sellers, permit buyers: China and Canada's roles in a global low-carbon society. Climate Policy 8, S93-S107 (2008).

50. Garibaldi, J. A. et al. Comparative analysis of five case studies: commonalities and differences in approaches to mitigation actions in five developing countries. Climate and Development 6 , 59-70 (2014).

51. Strachan, N., Foxon, T. \& Fujino, J. Low-Carbon Society (LCS) modelling. Climate Policy 8, S3S4 (2008).

52. Kainuma, M., Shukla, P. R. \& Jiang, K. Framing and modeling of a low carbon society: An overview. Energy Economics 34, S316-S324 (2012).

53. Pye, S. et al. Exploring national decarbonization pathways and global energy trade flows: a 
multi-scale analysis. Climate Policy 16, 1-18 (2016).

54. Deep Decarbonization Pathways Project - SDSN/IDDRI. Pathways To Deep Decarbonization 2015 Synthesis Report. (2015). Available at: http://deepdecarbonization.org/wpcontent/uploads/2016/03/DDPP_2015_REPORT.pdf.

55. Bataille, C., Waisman, H., Colombier, M., Segafredo, L. \& Williams, J. The Deep Decarbonization Pathways Project (DDPP): insights and emerging issues. Climate Policy 16, S1-S6 (2016).

56. Bataille, C. et al. The need for national deep decarbonization pathways for effective climate policy. Climate Policy 16, S7-S26 (2016).

57. Argyriou, M. et al. The impact of the Deep Decarbonization Pathways Project (DDPP) on domestic decision-making processes - Lessons from three countries. Iss. Brief 11 (2016). Available at: http://www.iddri.org/Publications/2050-low-emission-pathways-domesticbenefits-and-methodological-insights-Lessons-from-the-DDPP.

58. Bataille, C. Case Study: The Deep Decarbonization Pathways Project. 1-12 (2018). Available at: https://wriorg.s3.amazonaws.com/s3fs-public/deep-decarbonization-pathwaysproject.pdf?_ga=2.22835515.1410827332.1544034123-563742113.1542824149.

59. Cherp, A., Vinichenko, V., Jewell, J., Brutschin, E. \& Sovacool, B. Integrating techno-economic, socio-technical and political perspectives on national energy transitions: A meta-theoretical framework. Energy Research \& Social Science 37, 175-190 (2018).

60. Davis, S. J. et al. Net-zero emissions energy systems. Science 9793, (2018).

61. Lempert, R. J. Shaping the Next One Hundred Years: New Methods for Quantitative, LongTerm Policy Analysis. (2003). doi:10.1016/j.techfore.2003.09.006

62. Morgon, G. \& Henrion, M. Uncertainty: A Guide to Dealing With Uncertainty In Quantiative Risk and Policy Analysis. (Cambridge University Press, 1990).

63. Mathy, S., Criqui, P., Knoop, K., Fischedick, M. \& Samadi, S. Uncertainty management and the dynamic adjustment of deep decarbonization pathways. Climate Policy 16, S47-S62 (2016).

64. Lempert, R. J. et al. A general, analytic method for generating robust strategies and narrative scenarios. Management Science 52, 514-528 (2006).

65. Haasnoot, M., Kwakkel, J. H., Walker, W. E. \& ter Maat, J. Dynamic adaptive policy pathways: A method for crafting robust decisions for a deeply uncertain world. Global Environmental Change 23, 485-498 (2013).

66. Maier, H. R. et al. An uncertain future, deep uncertainty, scenarios, robustness and adaptation: How do they fit together? Environmental Modelling and Software 81, 154-164 (2016).

67. Bataille, C., Sawyer, D. \& Melton, N. Pathways to deep decarbonization in Canada. (2015). Available at: http://deepdecarbonization.org/wp-content/uploads/2015/09/DDPP_CAN.pdf. (Accessed: 19th April 2017)

68. Altieri, K. et al. Pathways to deep decarbonization in South Africa. (2015). Available at: http://deepdecarbonization.org/wp-content/uploads/2015/09/DDPP_ZAF.pdf. (Accessed: 19th April 2017) 
69. Virdis, M.-R. et al. Pathways to deep decarbonization in Italy. (2015). Available at: http://deepdecarbonization.org/wp-content/uploads/2015/09/DDPP_ITA.pdf. (Accessed: 20th April 2017)

70. Shukla, P., Dhar, S., Pathak, M., Mahadevia, D. \& Garg, A. Pathways to deep decarbonization in India. (2015). Available at: http://deepdecarbonization.org/wpcontent/uploads/2015/09/DDPP_IND.pdf. (Accessed: 19th April 2017)

71. Criqui, P., Mathy, S. \& Hourcade, J.-C. Pathways to deep decarbonization in France. (2015). Available at: http://deepdecarbonization.org/wp-content/uploads/2015/09/DDPP_FRA.pdf. (Accessed: 20th April 2017)

72. Kainuma, M., Masui, T., Oshiro, K. \& Hibino, G. Pathways to deep decarbonization in Japan. (2015).

73. Hillebrandt, K., Samadi, S. \& Fischedick, M. Pathways to deep decarbonization in Germany. (2015). Available at: http://deepdecarbonization.org/wpcontent/uploads/2015/09/DDPP_DEU.pdf. (Accessed: 20th April 2017)

74. Liu, Q. et al. Pathways to deep decarbonization in China. (2015). Available at: http://deepdecarbonization.org/wp-content/uploads/2015/09/DDPP_CHN.pdf. (Accessed: 19th April 2017)

75. Pye, S., Anandarajah, G., Fais, B., McGlade, C. \& Strachan, N. Pathways to deep decarbonization in the United Kingdom. (2015). Available at: http://deepdecarbonization.org/wp-content/uploads/2015/09/DDPP_GBR.pdf. (Accessed: 19th April 2017)

76. Pfenninger, S., Hawkes, A. \& Keirstead, J. Energy systems modeling for twenty-first century energy challenges. Renewable and Sustainable Energy Reviews 33, 74-86 (2014).

77. Altieri, K. E. et al. Achieving development and mitigation objectives through a decarbonization development pathway in South Africa. Climate Policy 16, s78-s91 (2016).

78. Oshiro, K., Kainuma, M. \& Masui, T. Assessing decarbonization pathways and their implications for energy security policies in Japan. Climate Policy 16, S63-S77 (2016).

79. Denis, A. et al. Pathways to deep decarbonisation in 2050: how Australia can prosper in a low carbon world. (2014). Available at: http://deepdecarbonization.org/wpcontent/uploads/2015/09/AU_DDPP_Report_Final.pdf.

80. La Rovere, E., Gesteira, C., Grottera, C. \& Wills, W. Pathways to deep decarbonization in Brazil. (2015). Available at: http://deepdecarbonization.org/wpcontent/uploads/2015/12/DDPP_BRA.pdf. (Accessed: 19th April 2017)

81. Williams, J. et al. Pathways to Deep Decarbonization in the United States. (2014). Available at: http://deepdecarbonization.org/wp-

content/uploads/2015/11/US_Deep_Decarbonization_Technical_Report.pdf. (Accessed: 21st April 2017)

82. Denis-Ryan, A., Bataille, C. \& Jotzo, F. Managing carbon-intensive materials in a decarbonizing world without a global price on carbon. Climate Policy 16, S110-S128 (2016).

83. Bataille, C. et al. A review of technology and policy deep decarbonization pathway options for making energy intensive industry production consistent with the Paris Agreement. Journal of 
Cleaner Production 187, 960-973 (2018).

84. Bruckner, T. et al. in Climate Change 2014: Mitigation of Climate Change. Contribution of Working Group III to the Fifth Assessment Report of the Intergovernmental Panel on Climate Change 511-597 (Cambridge University Press, 2014). doi:10.1017/СBO9781107415416

85. McDowall, W. Exploring possible transition pathways for hydrogen energy: A hybrid approach using socio-technical scenarios and energy system modelling. Futures 63, 1-14 (2014).

86. Trutnevyte, E. et al. Linking a storyline with multiple models: A cross-scale study of the UK power system transition. Technological Forecasting and Social Change 89, 26-42 (2014).

87. Robiou Du Pont, Y. et al. Equitable mitigation to achieve the Paris Agreement goals. Nature Climate Change 7, 38-43 (2017).

88. Kartha, S. et al. Cascading biases against poorer countries. Nature Climate Change 8, 348-349 (2018).

89. Zhang, Y. \& Shi, H.-L. From burden-sharing to opportunity-sharing: unlocking the climate negotiations. Climate Policy 14, 63-81 (2014).

90. Winkler, H. \& Rajamani, L. CBDR \& RC in a regime applicable to all. Climate Policy 14, 102-121 (2014).

91. Raupach, M. R. et al. Sharing a quota on cumulative carbon emissions. Nature Climate Change 4, (2014).

92. Pan, X., Elzen, M. den, Höhne, N., Teng, F. \& Wang, L. Exploring fair and ambitious mitigation contributions under the Paris Agreement goals. Environmental Science and Policy 74, 49-56 (2017).

93. Höhne, N., den Elzen, M. \& Escalante, D. Regional GHG reduction targets based on effort sharing: a comparison of studies. Climate Policy 14, 122-147 (2014).

94. 2050 Pathways Initiative. 2050 Pathways Initiative. Available at:

http://newsroom.unfccc.int/unfccc-newsroom/high-level-climate-champions-launch-2050pathways-platform/.

95. Masson-Delmotte, V. et al. IPCC Special Report: Global Warming of $1.5^{\circ} \mathrm{C}$. Summary for Policymakers. Intergovernmental Panel on Climate Change (2018). doi:10.1017/CBO9781107415324

96. Boer, R. et al. Pathways to deep decarbonizing agriculture, forest and other land-uses sector in Indonesia. (2016). Available at: http://deepdecarbonization.org/wpcontent/uploads/2017/02/DDPP_AFOLU_ID.pdf. (Accessed: 20th April 2017)

97. Rosenbloom, D. Pathways: An emerging concept for the theory and governance of low-carbon transitions. Global Environmental Change 43, 37-50 (2017).

98. Turnheim, B. et al. Evaluating sustainability transitions pathways: Bridging analytical approaches to address governance challenges. Global Environmental Change 35, 239-253 (2015).

99. Fortes, P., Alvarenga, A., Seixas, J. \& Rodrigues, S. Long-term energy scenarios: Bridging the gap between socio-economic storylines and energy modeling. Technological Forecasting and Social Change 91, 161-178 (2015). 